\title{
Alinhamento entre o planejamento estratégico e o plano diretor da TI em órgãos públicos federais*
}

\section{Alignment between strategic planning and IT master plan in federal public agencies}

Paulo Rogério Foina' Marivone Sacardi de Paranaiba ${ }^{2}$
* Recebido em: 20/11/2015. Aprovado em: 21/03/2017.

1 Físico, pela Universidade Federal de São Carlos (1976), Mestre em Computação pelo Instituto de Ciências Matemáticas de São Carlos - USP (1979) e Doutor em Informática pela Pontifícia Universidade Católica do Rio de Janeiro (1985). Atualmente é Coordenador de Graduação e Pós-Graduação do Centro Universitário de Brasília - UniCEUB e sócio gerente da Sistema de Informação e Tecnologia Ltda.

2 Pós-graduada Lato Sensu em Governança de Tecnologia da Informação.

\section{Resumo}

Neste trabalho analisamos o alinhamento entre Planejamento Estratégico institucional (PE) e o Plano Diretor de Tecnologia da Informação (PDTI) dos ministérios federais. Considerando-se que o primeiro direciona as ações da instituição e o segundo oferece suporte às ações institucionais e direciona a operacionalidade da área de TI, o alinhamento deles parece ser natural, mas não foi o que encontramos. Alguns ministérios não possuem o Planejamento Estratégico, e nesse caso consideramos o Plano Plurianual (PPA) 2012-2015. O levantamento desses instrumentos foi realizado por meio do site Acesso à Informação - Governo Federal. Nos órgãos que possuíam os dois instrumentos, o alinhamento encontrado foi satisfatório. Já para os órgãos que possuíam somente o instrumento PDTI, o resultado não foi satisfatório, havendo lacunas para algumas ações realizadas pela organização. O resultado da análise é que, quando os instrumentos existem e estão alinhados à área de TI do órgão, assume papel estratégico e relevante para o sucesso do mesmo..

Palavras-chave: Planejamento Estratégico. Plano Diretor de Tecnologia da Informação. Alinhamento.

\section{Abstract}

In this work, we analyze the alignment between institutional strategic planning (PE) and the Information Technology Master Plan (PDTI) of the federal ministries. Considering that the former directs the actions of the institution and the second supports the institutional actions and directs the operationality of the IT area, their alignment seems to be natural, but it was not what we found. Some ministries do not have Strategic Planning, in which case we consider the Multi-Year Plan (PPA) 2012-2015. The collection of these instruments was done through the Access to Information website - Federal Government. In the organs that had both instruments, the alignment was satisfactory. For the organs that only had the PDTI instrument, the result was not satisfactory, and there were gaps for some actions carried out by the organization. The result of the analysis is that when the instruments exist and are aligned to the IT area of the organ, it assumes a strategic and relevant role for the success of the same.

Keywords: Strategic Planning. Information Technology Master Plan. Alignment. 


\section{Introdução}

Com o vasto volume de conhecimento que é disponibilizado para a sociedade nos dias atuais, observa-se uma intensa busca das organizações privadas para adequação de seus processos internos a esses avanços, de forma que possam, mais rápida e efetivamente, responder aos interesses dos clientes, que buscam inovações e serviços de qualidade. Para se manterem competitivas, as organizações precisam estar, sempre, em contínuo processo de aprendizado e aperfeiçoamento, procurando adaptar seus processos e sua estrutura organizacional a essas novas realidades, que podem representar ameaças e/ou oportunidades para os negócios. É nesse cenário que entra o Planejamento Estratégico (PE), que "é um processo de formulação de estratégia organizacional no qual se busca a inserção da organização e de sua missão no ambiente em que ela está atuando" (CHIAVENATO, 2003, p. 39). É considerada, por muitos especialistas, uma importante ferramenta para o gerenciamento de informações e que tem como objetivo ajudar a organização na tomada de decisões para períodos de curto, médio e longo prazo.

Constam do ordenamento jurídico vigente normas que procuram orientar e regular a gestão das Organizações Públicas, como o art. $6^{\circ}$, inciso I do Decreto Lei 200/1967, que prevê que o planejamento é um princípio fundamental da Administração Pública, sendo que o planejamento é particularmente crítico para o sucesso da área da Tecnologia da Informação (TI).

"A TI evoluiu de uma orientação tradicional de suporte administrativo para um papel estratégico dentro da organização" (LAURINDO et al., 2001, p. 2). Assumindo esse novo papel, a área da TI também abraçou novas responsabilidades e, juntamente a estas, foram surgindo necessidades, como a criação de normas para a regulamentação do desenvolvimento de suas atividades.

Com a tentativa de buscar o alinhamento estratégico da TI com as áreas finalísticas da organização, com vistas à otimização do uso dos recursos públicos, foi criada, em 2008, pelo Secretário de Logística e Tecnologia da Informação do Ministério do Planejamento Orçamento e Gestão, a Instrução Normativa (IN) da Secretaria de Logística e Tecnologia da Informação (SLTI) 04, que disciplina o processo de contratação de serviços de Tecnologia da Informação pela Administração Pública. A norma, em seu art. $4^{\circ}$, estabelece: "as contratações de que trata esta Instrução Normativa deverão ser precedidas de planejamento, elaborado em harmonia com o Plano Diretor de Tecnologia da Informação (PDTI), alinhado ao planejamento estratégico do órgão ou entidade", ou seja, a área de Tecnologia da Informação precisa desenvolver um instrumento que descreva o planejamento de todas suas ações por um determinado período, cujo teor deverá estar alinhado com o Planejamento Estratégico da organização. Nas situações em que inexiste um Planejamento Estratégico, tal instrumento deverá estar alinhado com o Plano Plurianual (PPA) ou instrumento equivalente.

Entende-se que o alinhamento entre esses dois instrumentos, o Planejamento Estratégico (PE) e Plano Diretor de Tecnologia da Informação (PDTI) conseguem estabelecer um direcionamento correto para a execução do cronograma planejado e, por conseguinte, a excelência na utilização dos recursos públicos.

Para a realização deste trabalho, usamos, além da revisão bibliográfica, um estudo analítico sobre os instrumentos PE e PDTI dos Ministérios com sede em Brasília e que possuem orçamentos significativos de TI. A coleta de informações necessárias ao estudo foi feita por meio do site "Acesso à Informação - Governo Federal", no link http://www.acessoainformacao.gov.br/. Essa solicitação está amparada pela a Lei no 12.527/2012 (Lei de acesso a Informação - LAI), que regulamenta o direito constitucional de acesso às informações públicas.

\section{Referencial Teórico}

Segundo Bolan (1974 apud MINTZBERG, 2004, p. 22), "planejamento denota pensar no futuro". Com visão de controle sobre o futuro, escreveu Ackoff (apud MINTZBERG, 2004, p. 23) "planejamento é o projeto de um futuro desejado e de maneiras efetivas de realizá-lo". Já Koontz (1958 apud MINTZBERG, 2004, p. 24) o definiu como um processo que visa à tomada de decisões ". a determinação consciente de medidas destinadas a cumprir objetivos. Planejar é, portanto, decidir”. Dror (1971 apud MINTZBERG, 2004, p. 23) resume-o em uma palavra "planejamento, em uma palavra, é administração". E Gulick, (apud CHIAVENATO, 2004, p. 87) com propriedade, o define como "a tarefa de traçar as linhas gerais do que deve ser feito e dos métodos de fazê-lo, a fim de atingir os objetivos da empresa".

Para a palavra estratégia, também não foi encontrada uma definição que seja universalmente aceita. São muitos os autores que a conceituam de forma distinta, como 
Wright, Kroll e Parnell (2000, p. 34) expõe que "Estratégia se refere aos planos da alta administração para alcançar resultados consistentes com a missão e os objetivos gerais da organização". Já Chiavenato (2003, p. 38) definiu que "A estratégia significa o comportamento global da organização em relação ao ambiente que a circunda", para Porter (1999, p. 73) deve haver harmonia entre as atividades realizadas pela empresa. Ainda segundo Porter (1999, p. 80) "A estratégia torna as escolhas sobre o que não fazer tão importante quanto às escolhas sobre o que fazer".

Para Chiavenato (2003, p. 35), após a Segunda Guerra Mundial, os conceitos sobre planejamento estratégico formal e tradicional, antes empregados na área militar, começaram a ser usados no mundo empresarial. $\mathrm{O}$ planejamento estratégico passou a ser responsável por determinar quais seriam as estratégias necessárias para uma empresa alcançar suas metas estabelecidas. E, como havia poucas mudanças no mundo dos negócios, o planejamento estratégico era definido com prazos de 5 a 10 anos.

A globalização, as constantes mudanças e o surgimento de inúmeras inovações tecnológicas, torna o planejamento estratégico indispensável nas organizações, mas com características diferentes. Deixou a forma rígida do passado e transformou-se em um elemento moldável para as necessidades de cada organização: contínuo, mais flexível e de fácil adaptação aos cenários. "À medida que as empresas cresceram e se tornaram mais complexas [...] precisaram de uma abordagem sistemática para definir estratégia. O planejamento estratégico surgiu como resposta" Porter (1987 apud MINTZBERG, 2004, p. 184).

Para Kotler (1992 apud RIBEIRO, 2012, p. 23), o "planejamento estratégico é definido como um processo gerencial de desenvolver e manter uma adequação razoável entre os objetivos e recursos da empresa e as mudanças e oportunidades de mercado".

Drucker (apud CHIAVENATO, 2003, p. 39) expõe sua definição para planejamento estratégico da seguinte maneira:

Planejamento estratégico é o processo continuo de sistematicamente e, com maior conhecimento do futuro contido, tomar decisões atuais que envolvem riscos; organizar, sistematicamente, as atividades necessárias à execução dessas decisões e, por meio de uma retroalimentação organizada e sistemática, medir o resultado dessas decisões em confronto com as expectativas alimentadas.

Rasmussen (1990, p. 57) ainda destaca a importância que o planejamento estratégico representa para o crescimento das organizações e também menciona o comprometimento que cada nível hierárquico precisa manter com as metas estratégicas planejadas durante a concepção desse planejamento.

\section{Planejamento de Tecnologia de Informação}

Pode-se dizer que, praticamente, todas as áreas de uma organização dependem de recursos desenvolvidos pela área de TI, fazendo com que esta passe a desempenhar um papel de grande importância estratégica nas organizações. Mcgee e Prusak (1994 apud WEBSTER; CASTRO, 2012, p. 23) comentam que a TI alterou o mundo dos negócios de forma irreversível, desde que foi introduzida, sistematicamente, na década de 1950.

Nos Órgãos Públicos Federais, essa realidade não é diferente. A TI é responsável por fornecer o apoio necessário para que estes possam atender às exigências da população que necessita de celeridade, eficiência e inovação nos serviços que lhes são prestados.

$\mathrm{O}$ instrumento Planejamento Estratégico de Tecnologia de Informação (PETI), é definido no Guia de Elaboração do PDTI do SISP (Sistema de Administração dos Recursos de Informação e Informática), versão 1.0, da forma que se segue:

O PETI, situado no nível estratégico, é um documento que complementa o Planejamento Estratégico Institucional, por meio do planejamento de sistemas de informação, conhecimentos e informática, possibilitando a definição de objetivos específicos para a área de TI. Ele estabelece as diretrizes e as metas que orientam a construção do Planejamento de TI do Órgão.

Para outros autores, o PETI é um documento que, também, envolve o nível tático Foina (2012, p. 25), define a sua elaboração em quatro etapas: a) Diagnóstico amplo da situação atual da empresa; b) Estabelecimento da situação desejada para o período de planejamento; c) Definição das políticas e diretrizes básicas; e d) Estabelecimento dos planos de ação (táticos).

Seja do nível estratégico, estratégico/tático ou estratégico/tático/operacional, o PETI deve garantir o alinhamento dos objetivos estratégicos da área de TI com os objetivos estratégicos do negócio da organização. Audy (2008, p. 68) apresenta uma excelente descrição sobre a importância desse alinhamento. "Essa integração, chamada de alinhamento estratégico entre as funções de TI e os objetivos organizacionais, tem sido apontada como 
um dos principais fatores de retorno do investimento e de agregação de valor de negócio”.

O Plano Diretor de Tecnologia da Informação (PDTI) é um instrumento de diagnóstico, planejamento e gestão dos recursos e processos de Tecnologia da Informação que visa atender às necessidades tecnológicas e de informação de um órgão ou entidade para um determinado período, essa definição é dada no inciso XXVII - Art. 20 da IN 04/2008.

O Guia de Elaboração de PDTI do SISP defini-o da seguinte forma “[...] PDTI é o instrumento que permite nortear e acompanhar a atuação da área de TI, definindo estratégias e o plano de ação para implantá-las”.

O PDTI, em grande parte das organizações privadas e públicas, será o único documento que a TI desenvolverá para o seu planejamento; portanto, abordará tanto elementos estratégico da TI como as ações táticas que definem as ações, metas e projetos a serem executados pela TI na organização.

É imprescindível que o PDTI alinhe as ações e os objetivos da TI com as metas e objetivos do negócio da organização, como comenta Luftman e Bullen (2004 apud BARROS, 2013, p. 15) “deve haver harmonização entre as metas e os planos de implementação de TI com as metas e a estrutura organizacionais".

O PDTI possui o papel de orientar o uso correto dos recursos da área de TI em uma organização. E a sua elaboração demonstra que essa organização está preocupada em usar as melhores práticas existentes no mercado de tecnologia para obter resultados com eficiência e eficácia e, portanto, efetividade.

Entende-se que, nesse mesmo contexto, a área de TI na Administração Pública Federal, deve, obrigatoriamente, desenvolver um bom trabalho de planejamento, visto que a sociedade clama por sistemas de informação providos de agilidade, praticidade e confiabilidade.

Segundo um levantamento realizado no ano de 2007 pelo Tribunal de Contas da União (TCU), os principais problemas identificados na Governança de Tecnologia da Informação na Administração Pública Federal remetiam às seguintes áreas: planejamento estratégico institucional e de TI, estrutura de pessoal de TI, desenvolvimento de sistemas, gestão de acordos de níveis de serviço, processo de contratação de bens e serviços de TI, processo de gestão de contratos de TI, processo orçamentário de TI, auditoria de tecnologia da informação e, especialmente em situação crítica, a segurança da informa- ção. O resultado desse levantamento resultou no Acórdão 1.603/2008-TCU-Plenário.

O Acórdão 1.603/2008-TCU-plenário recomendava, entre muitas ações, a de:

Promover ações com o objetivo de disseminar a importância do Planejamento Estratégico, procedendo, inclusive mediante orientação normativa, ações voltadas à implantação e/ou aperfeiçoamento de Planejamento Estratégico Institucional, Planejamento Estratégico de TI e comitê diretivo de TI, com vistas a propiciar a alocação dos recursos públicos conforme as necessidades e prioridades da organização.

No levantamento realizado pelo TCU, em 2012, $85 \%$ das organizações participantes afirmaram realizar o Planejamento Estratégico Institucional, 78\% o Planejamento Estratégico de TI e 54\% o Plano Diretor de TI. A pesquisa culminou no Acórdão 2.585/2012-TCU-Plenário. Esse Acórdão recomendava ao Conselho Nacional de Justiça, ao Conselho Nacional do Ministério Público, à Secretaria de Logística e Tecnologia da Informação e à Comissão Interministerial de Governança Corporativa e de Administração de Participações Societárias da União, que orientassem as organizações sobre a sua jurisdição para que, entre outras ações:

Em atenção ao art. $6^{\circ}$ da Lei 12.527/2011 e aos princípios da transparência e da prestação de contas, implementem instrumentos de planejamento estratégico institucional e de tecnologia da informação, dando-lhes ampla divulgação, com exceção das informações classificadas como não públicas, nos termos da lei;

Definam e formalizem metas de governança, como parte do Plano Diretor de Tecnologia da Informação da instituição, baseadas em parâmetros de governança, necessidades do negócio e riscos relevantes, atentando para as metas legais de cumprimento obrigatório e as orientações da ABNT NBR ISO/IEC 31000;

No ano de 2008, foi criada a IN SLTI 04 para disciplinar o processo de contratação de serviços de Tecnologia da Informação pela Administração Pública Direta, autárquica e fundacional do Poder Executivo da União. É um ato normativo expedido por autoridades administrativas, norma complementar às leis, aos decretos, aos tratados e às convenções internacionais. Não podem transpor, inovar ou modificar o texto da norma que complementam. $\mathrm{O}$ Art. $3^{\circ}$ afirma que, anualmente, a SISP é responsável por elaborar e disponibilizar a Estratégia Geral de Tecnologia da Informação e Comunicação (EGTIC). Tal documento servirá de subsídio à elaboração dos PDTI pelos órgãos e entidades integrantes do SISP. 
O Art. $4^{\circ}$ aborda a necessidade de que as contratações pertinentes à IN sejam precedidas de planejamento, e este deve ser elaborado em harmonia com o Plano Diretor de Tecnologia da Informação - PDTI. O PDTI deve estar alinhado ao Plano Estratégico da organização, sendo necessário ser aprovado pelo Comitê de Tecnologia da Informação do órgão. No caso de o órgão não possuir o
Plano Estratégico, deve-se informar a ausência no PDTI e a opção pela utilização de um documento equivalente, como o Plano Plurianual (PPA).

\section{Estudo de Caso}

Foram consultados 24 (vinte e quatro) Ministérios, os quais se encontram relacionados no Quadro 1.

Quadro 1 - Lista de Instrumentos por Ministérios

\begin{tabular}{|c|c|c|c|}
\hline Ministérios & $\mathrm{PE}$ & PETI & PDTI \\
\hline MAPA - Agricultura, Pecuária e Abastecimento. & $S$ & $\mathrm{~N}$ & $S$ \\
\hline$M C$ - Comunicações & $\mathrm{N}$ & $S$ & $S$ \\
\hline MCIDADES - Cidades & $S$ & $\mathrm{~N}$ & $S$ \\
\hline MCTI - Ciência, Tecnologia e Inovação & $S$ & $\mathrm{~N}$ & $S$ \\
\hline MD - Defesa & $\mathrm{N}$ & $\mathrm{N}$ & $S$ \\
\hline MDA - Desenvolvimento Agrário & $S$ & $\mathrm{~N}$ & $\mathrm{~N}$ \\
\hline MDIC - Desenvolvimento, Indústria e Comércio Exterior. & $S$ & $S$ & $S$ \\
\hline MDS - Desenvolvimento Social e Combate à Fome & $\mathrm{N}$ & $\mathrm{N}$ & $S$ \\
\hline ME - Esporte & $\mathrm{N}$ & $\mathrm{N}$ & $S$ \\
\hline MEC - Educação & $\mathrm{N}$ & $\mathrm{N}$ & $S$ \\
\hline MF - Fazenda & $S$ & $\mathrm{~N}$ & $\mathrm{~N}$ \\
\hline MI - Integração Nacional & $S$ & $\mathrm{~N}$ & $S$ \\
\hline MINC - Cultura & $S$ & $\mathrm{~N}$ & $S$ \\
\hline MJ - Justiça & $\mathrm{N}$ & $\mathrm{N}$ & $S$ \\
\hline MMA - Meio Ambiente & $S$ & $\mathrm{~N}$ & $S$ \\
\hline MME - Minas e Energia & $\mathrm{N}$ & $\mathrm{N}$ & $\mathrm{N}$ \\
\hline MPA - Pesca e Aquicultura & $\mathrm{N}$ & $\mathrm{N}$ & $S$ \\
\hline MPOG - Planejamento, Orçamento e Gestão. & $S$ & $S$ & $S$ \\
\hline MPS - Previdência Social & $S$ & $\mathrm{~N}$ & $S$ \\
\hline MRE - Relações Exteriores & $\mathrm{N}$ & $\mathrm{N}$ & $S$ \\
\hline MS - Saúde & $S$ & $\mathrm{~N}$ & $S$ \\
\hline MT - Transportes & $\mathrm{N}$ & $\mathrm{N}$ & $S$ \\
\hline MTE-Trabalho e Emprego & $S$ & $\mathrm{~N}$ & $\mathrm{~N}$ \\
\hline MTUR - Turismo & $S$ & $S$ & $S$ \\
\hline
\end{tabular}

Fonte: Pesquisa realizada pelo estudo.

$\mathrm{O}$ resultado da pesquisa nos mostrou que apenas 14 (quatorze) dos 24 (vinte e quatro) ministérios possuem o instrumento PE. Dez ministérios, portanto, ainda não desenvolveram esse instrumento essencial, apesar de que sua elaboração seja recomendada pelo Decreto-Lei $n^{\circ}$ 200/1967, Art. 06 e 07, pela Constituição de 1988, Art. 174 e pela Lei 10.180/2001 Art. 07, conforme anteriormente exposto no item 2.2.3 Normas e Legislação para os Órgãos Públicos Brasileiros, do presente estudo. Infelizmente, esses números evidenciam que o Planejamento Estratégico não é prioridade para os gestores desses órgãos.

Já os números para o instrumento PDTI são mais animadores, uma vez que 20 (vinte) dos 24(vinte quatros) possuem tal instrumento. Mas isso não evidencia que os gestores da área de TI estejam realmente preocupados em planejar suas ações, haja vista a existência de Acórdãos do TCU e a IN SLTI 04 que obrigam a elaboração do PDTI. Apesar da legislação que torna a exigência obrigatória, há 4 (quatro) ministérios que, ainda, não dispõe desse instrumento. 
O critério para selecionar os órgãos que foram analisados foi baseado no valor total da dotação atualizada que cada órgão obteve para a "Subfunção" 126 - Tecnologia da Informação" no Orçamento do ano de 2014.

A Tabela 1 apresenta os valores orçamentários que cada órgão obteve em ordem decrescente. alinhamento com as ações de planejamento do PDTI com as ações de planejamento do PPA 2012-2015.

\section{Ministério da Saúde - MS}

O PE disponibilizado pelo MS apresenta dezesseis objetivos estratégicos, com explicação do que se trata cada objetivo e também quais as ações estratégicas a se-

Tabela 1 - Dotação Orçamentária para a Subfunção - 126 Tecnologia da Informação

\begin{tabular}{|c|c|c|c|c|c|}
\hline \multicolumn{2}{|c|}{ Órgão Superior } & \multirow{2}{*}{$\begin{array}{c}\text { Dotação Atualizada } \\
1.678 .194 .395,00\end{array}$} & \multirow{2}{*}{$\begin{array}{c}\text { Empenhos Emitidos } \\
3.903 .965 .758,96\end{array}$} & \multirow{2}{*}{$\begin{array}{c}\text { Despesas Executadas } \\
3.802 .133 .542,09\end{array}$} & \multirow{2}{*}{$\begin{array}{l}\text { Valores Pagos } \\
3.036 .249 .878,88\end{array}$} \\
\hline 25000 & Ministério da Fazenda & & & & \\
\hline 36000 & Ministério da Saúde & $524.833 .750,00$ & $452.163 .288,26$ & $452.163 .288,26$ & $335.706 .958,75$ \\
\hline 33000 & Ministério da Previdência Social & $356.364 .000,00$ & $389.027 .491,73$ & $389.027 .491,73$ & $371.936 .351,77$ \\
\hline 20113 & $\begin{array}{l}\text { Ministério do Planejamento, Orçamento } \\
\text { e Gestão. }\end{array}$ & $305.443 .331,00$ & $245.596 .860,16$ & $245.596 .860,16$ & $190.957 .317,98$ \\
\hline 41000 & Ministério das Comunicaçōes & $160.354 .000,00$ & $51.418 .878,91$ & $51.418 .878,91$ & $896.800,00$ \\
\hline 38000 & Ministério do Trabalho e Emprego & $93.676 .701,00$ & $92.755 .571,75$ & $92.755 .571,75$ & $88.228 .550,89$ \\
\hline 55000 & $\begin{array}{l}\text { Ministério do Desenv. Social e Combate } \\
\text { a Fome }\end{array}$ & $79.612 .602,00$ & $19.922 .578,39$ & $19.922 .578,39$ & $11.447 .476,70$ \\
\hline 52000 & Ministério da Defesa & $70.000 .000,00$ & $62.348 .451,89$ & $62.348 .451,87$ & $24.479 .899,07$ \\
\hline 24000 & $\begin{array}{l}\text { Ministério da Ciência, Tecnologia e } \\
\text { Inovação. }\end{array}$ & $18.766 .721,00$ & 27.311.587,91 & $26.234 .508,94$ & $13.134 .576,88$ \\
\hline 32000 & Ministério de Minas e Energia & $14.440 .000,00$ & $13.236 .528,95$ & $13.236 .528,95$ & $5.055 .520,58$ \\
\hline 56000 & Ministério das Cidades & $1.468 .584,00$ & - & - & - \\
\hline 35000 & Ministério das Relações Exteriores & $631.000,00$ & $70.333,30$ & $70.333,30$ & $70.333,30$ \\
\hline 26000 & Ministério da Educação & - & $10.541 .830,77$ & $10.541 .830,77$ & $4.128 .715,64$ \\
\hline Total g & & $3.303 .785 .084,00$ & 5.268.359.160,98 & $5.165 .449 .865,12$ & 4.082.292.380,44 \\
\hline
\end{tabular}

Fonte: Sistema Integrado de Administração Financeira - SIAFI - Data: 03/03/2015.

Pela ordem de maior valor de dotação atualizada, foram analisados os órgãos que possuem PE e PDTI, ou seja, o Ministério da Saúde e o Ministério de Previdência Social), para os quais foi verificado o alinhamento entre esses dois instrumentos. Semelhante análise foi efetuada para os órgãos que possuem somente o PDTI (Ministério das Comunicações e o Ministério do Desenvolvimento Social e Combate à Fome) para os quais foi verificado o

Subfunção representa um nível de agregação imediatamente inferior à função e deve evidenciar a natureza da atuação governamental. De acordo com a Portaria no 42, de 14 de abril de 1999, é possível combinar as subfunções a funções diferentes daquelas a elas diretamente relacionadas, o que se denomina matricialidade. Conforme Manual Técnico de Orçamento - MTO 2015.

rem adotadas para se alcançar as metas estabelecidas. O

Quadro 2 apresenta esses objetivos estratégicos.

Quadro 2 - Objetivos Estratégicos do MS

\begin{tabular}{|c|c|}
\hline $\begin{array}{l}\text { Códi- } \\
\text { go }\end{array}$ & Descrição dos Objetivos \\
\hline $\mathrm{OE} 01$ & $\begin{array}{l}\text { Garantir acesso da população a serviç̧os de qualidade, com equidade e em tempo adequado ao atendi- } \\
\text { mento das necessidades de saúde, aprimorando a política de Atençăo Básica e a Atenção Especializada. }\end{array}$ \\
\hline $\mathrm{O}=02$ & $\begin{array}{l}\text { Reduzir os riscos e agravos à saúde da população, por meio das açōes de promoção e vigilância em } \\
\text { saúde. }\end{array}$ \\
\hline $\mathrm{OE} 03$ & $\begin{array}{l}\text { Promover atenção integral à saúde da mulher e da criança e implementar a Rede Cegonha, com } \\
\text { especial atençăo às áreas e populaçōes de maior vulnerabilidade. }\end{array}$ \\
\hline OE04 & $\begin{array}{l}\text { Aprimorar a rede de urgência e emergência, com expansão e adequação de UPAs, Samu, PS e centrais } \\
\text { de regulação, articulando-a com outras redes de atenção. }\end{array}$ \\
\hline OE05 & $\begin{array}{l}\text { Fortalecer a rede de saúde mental, com ênfase no enfrentamento da dependência de crack e de outras } \\
\text { drogas. }\end{array}$ \\
\hline OE06 & $\begin{array}{l}\text { Garantir a atenção integral à saúde da pessoa idosa e dos portadores de doenças crônicas, estimulando } \\
\text { o envelhecimento ativo e saudável e fortalecendo as açōes de promoçăo e prevenção. }\end{array}$ \\
\hline OE07 & $\begin{array}{l}\text { Implementar o Subsistema de Atenção à Saúde Indígena, articulado com o SUS, baseado no cuidado } \\
\text { integral, observando as práticas de saúde e as medicinas tradicionais, com controle social, garantindo o } \\
\text { respeito às especificidades culturais. }\end{array}$ \\
\hline
\end{tabular}




\begin{tabular}{|c|c|}
\hline $\begin{array}{l}\text { Códi- } \\
\text { go }\end{array}$ & Descrição dos Objetivos \\
\hline OE08 & $\begin{array}{l}\text { Contribuir para a adequada formaçăo, alocação, qualificação, valorização e democratizaçăo das relaçōes } \\
\text { do trabalho dos profissionais e trabalhadores de Saúde. }\end{array}$ \\
\hline OEO9 & $\begin{array}{l}\text { Implementar novo modelo de gestão e instrumentos de relação federativa, com centralidade na garan- } \\
\text { tia do acesso, gestão participativa com foco em resultados, participaçăo social e financiamento estável }\end{array}$ \\
\hline OE10 & Qualificar instrumentos de execução direta, gerando ganhos de produtividade e eficiência para o SUS \\
\hline OE11 & Garantir assistência farmacêutica no âmbito do SUS. \\
\hline $0 E 12$ & $\begin{array}{l}\text { Fortalecer o complexo industrial e de ciência, tecnologia e inovação em Saúde como vetor estruturante } \\
\text { da agenda nacional de desenvolvimento econômico, social e sustentável, reduzindo a vulnerabilidade } \\
\text { do acesso à saúde e da assistência farmacêutica no âmbito do Sus. }\end{array}$ \\
\hline OE 13 & $\begin{array}{l}\text { Aprimorar a regulação e a fiscalização da Saúde Suplementar, articulando a relação público-privado, } \\
\text { gerando maior racionalidade e qualidade no setor Saúde. }\end{array}$ \\
\hline OE14 & $\begin{array}{l}\text { Promover internacionalmente os interesses brasileiros no campo da } \\
\text { Saúde, bem como compartilhar as experiências e saberes do SUS com outros paises, em conformidade } \\
\text { com as diretrizes da Política Externa Brasileira. }\end{array}$ \\
\hline 0 E15 & $\begin{array}{l}\text { Implementar açōes de saneamento básico e saúde ambiental, de forma sustentável, para a promoçăo } \\
\text { da saúde e reduçäo das desigualdades sociais. }\end{array}$ \\
\hline OE016 & Contribuir para erradicar a extrema pobreza no País. \\
\hline
\end{tabular}

Fonte: Planejamento Estratégico (2011 - 2015) do MS.

Após análise dos objetivos definidos pelo MS, compreende-se que estes estão alinhados com a missão apresentada pelo órgão e que estes são estratégicos. Chega-se a essa conclusão observando-se que existe uma preocupação em desenvolver ações que visem soluções tanto para o presente como para o futuro. E que, na definição dessas ações, existe o cuidado em apresentar ações que apontem soluções para o ambiente externo e, também, para o ambiente interno do órgão.

O Quadro 3 apresenta os objetivos estratégicos de TI que o MS planejou desenvolver nos anos de 2014 e 2015 em seu PDTI.

Quadro 3 - Objetivos Estratégicos da TI do MS

\begin{tabular}{|l|l|}
\hline Código & Descrição dos Objetivos \\
\hline OET101 & Aperfeiçoar a gestão orçamentária e financeira de TI. \\
\hline OET102 & Aprimorar o processo de capacitação em TI. \\
\hline OET103 & Aperfeiçoar a gestão de pessoas de TI. \\
\hline OET104 & Estabelecer padrões de segurança da informação. \\
\hline OET105 & $\begin{array}{l}\text { Estabelecer mecanismos de monitoramento e avaliação dos sistemas e } \\
\text { processos de TI. }\end{array}$ \\
\hline OET106 & Adotar padrões tecnológicos e de intercâmbio de dados em saúde. \\
\hline OETI07 & Fortalecer a governança de TI no MS. \\
\hline OET108 & Institucionalizar a implantação da política de geoinformação. \\
\hline OET109 & $\begin{array}{l}\text { Garantir a capacidade do MS de atender à demanda de infraestrutura } \\
\text { necessária ao funcionamento do SUS. }\end{array}$ \\
\hline OET110 & $\begin{array}{l}\text { Prover sistemas de informação para o MS e aperfeiçoar o modelo de } \\
\text { desenvolvimento de sistemas. }\end{array}$ \\
\hline OET111 & Promover a integração das informações de saúde. \\
\hline OET112 & $\begin{array}{l}\text { Promover e fortalecer as açães de TI que contribuam com o efetivo acesso à } \\
\text { atenção à saúde, o governo aberto, e o engajamento da sociedade. }\end{array}$ \\
\hline
\end{tabular}

Fonte: Plano de Diretor de Tecnologia da Informação do MS (2014-2015).
Observa-se que os objetivos estratégicos de TI se encontram, em sua totalidade, alinhados com os objetivos estratégicos institucionais. Os objetivos definidos no PDTI perseguem ações que visam soluções para o presente e para o futuro e, ainda que essas ações não se restrinjam ao público da TI, mas a todos os servidores do MS e também, em última análise, à sociedade brasileira. Para cada objetivo, são definidos os indicadores e as respectivas metas e, por fim, os projetos/ações que têm por finalidade garantir o alvo que se persegue no futuro.

O Quadro 4 deixa explícito o alinhamento entre os objetivos estratégicos de TI e os objetivos estratégicos institucionais.

Quadro 4 - Alinhamento entre os Objetivos Estratégicos e Objetivos Estratégicos da TI do MS

\begin{tabular}{|c|c|}
\hline Código - Objetivo Estratégico TI & Código - Objetivo Estratégico Institucional \\
\hline OET105 & OE09 e 0E10 \\
\hline OET106 & OE09, 0E13 e 0E14 \\
\hline OET107 & OE09 e 0E10 \\
\hline OET108 & Todos \\
\hline OET109 & Todos \\
\hline OET110 & OE09 e 0E10 \\
\hline OETI11 & Todos \\
\hline OET112 & Todos \\
\hline OET101 & 0E10 \\
\hline OETI02 & OE08 \\
\hline ET103 & OE08 \\
\hline OET104 & OE09 e 0E12 \\
\hline
\end{tabular}

Fonte: Plano de Diretor de Tecnologia da Informação do MS (2014-2015) e análise do autor.

\section{Ministério da Previdência Social}

O Ministério da Previdência Social (MPS) descreve sua missão da seguinte forma "garantir proteção ao trabalhador e sua família, por meio de sistema público de política previdenciária solidária, inclusiva e sustentável, com o objetivo de promover o bem-estar social".

O PE, ou Plano de ação Integrada - PAI, disponibilizado pelo MPS, traz os objetivos estratégicos de forma resumida. O Quadro 5 apresenta esses objetivos. 
Quadro 5 - Objetivos Estratégicos do MPS

\begin{tabular}{|c|c|}
\hline Código & Descrição dos Objetivos \\
\hline OE01 & Otimizar o quadro de pessoal e desenvolver competências compatíveis com os objetivos institucionais \\
\hline $0 \mathrm{E} 02$ & Desenvolver cultura voltada aos valores, aos resultados e à responsabilidade socioambiental. \\
\hline OE03 & Aperfeiçoar a aplicação dos recursos \\
\hline $0 \mathrm{E} 05$ & Promover políticas de sustentabilidade do sistema previdenciário \\
\hline 0E06 & Fortalecer os controles internos, o combate às fraudes, a gestão de riscos e a segurança institucional. \\
\hline OE07 & Aprimorar as informações sobre o perfil do cidadão e o mercado de trabalho \\
\hline OEO9 & Aperfeiçoar as decisões e minimizar as ocorrências de litígios \\
\hline 0E10 & Promover 0 acesso à informação de forma transparente e tempestiva \\
\hline $0 \mathrm{E} 11$ & Aprimorar a prevenção de riscos ocupacionais e mitigar os efeitos da incapacidade laboral \\
\hline $0 \mathrm{E} 12$ & Contribuir com a qualidade de vida dos contribuintes e beneficiários no envelhecimento ativo \\
\hline $0 \mathrm{E} 13$ & Intensificar a fiscalização dos regimes próprios e das entidades fechadas de previdência complementar \\
\hline $0 \mathrm{E} 14$ & Prover soluções em ambiente tecnológico integrado, seguro e de alto desempenho (Disponibilizados no Mapa Estratégico do órgão). \\
\hline $0 \mathrm{E} 15$ & Promover a valorização e a qualidade de vida das pessoas (Disponibilizados no Mapa Estratégico do órgão). \\
\hline
\end{tabular}

Fonte: Plano de Ação Integrado do MPS, para o exercício (2014).

O Quadro 6 apresenta os objetivos estratégicos de TI que o do MPS planejou desenvolver nos anos de 2014 e 2015 em seu PDTI.

\section{Quadro 6 - Objetivos Estratégicos da TI do MPS}

\begin{tabular}{|c|l|}
\hline Código & \multicolumn{1}{c|}{ Descrição dos Objetivos } \\
\hline OETI01 & Aprimorar a gestão de pessoas de TI \\
\hline OETI02 & Aperfeiçoar a gestão orçamentária de TI \\
\hline OETI03 & Aperfeiçoar a governança de TI \\
\hline OETI04 & Alcançar a efetividade na gestão de TI \\
\hline OETI05 & Fomentar a adoção de padrões tecnológicos e soluções de TI \\
\hline OETI06 & Garantir a segurança da informação e comunicações \\
\hline OETI07 & Fortalecer a integração e a comunicação institucional do SISP \\
\hline OETI08 & Promover a gestão de conhecimento do SISP \\
\hline OETI09 & $\begin{array}{l}\text { Melhorar continuamente a prestação de serviços e transparência de } \\
\text { informações à sociedade }\end{array}$ \\
\hline
\end{tabular}

Fonte: Plano de Diretor de Tecnologia da Informação do MPS (2014-2015).

Observa-se que a área de TI definiu objetivos que buscam complementar as soluções propostas pelos objetivos estratégicos institucionais. Que esses objetivos pro- serviços tanto para os usuários internos, servidores do órgão, como para os usuários externos, representados pela sociedade brasileira. Portanto, conclui-se que os dois planejamentos estão alinhados.

O Quadro 7 apresenta o alinhamento que se evidencia entre os objetivos estratégicos institucionais e os objetivos estratégicos de TI.

Quadro 7 - Alinhamento entre os Objetivos Estratégicos e Objetivos Estratégicos da TI do MPS

\begin{tabular}{|c|c|}
\hline Código - Objetivo Estratégico TI & Código - Objetivo Estratégico Institucional \\
\hline OET101 & OE15 e 0E1 \\
\hline OET102 & OE3 \\
\hline OET103 & OE14 \\
\hline OET104 & OE14 \\
\hline OET105 & OE14 \\
\hline OET106 & OE6 e 0E14 \\
\hline OET107 & OE14 \\
\hline OET108 & OE10 \\
\hline OET109 & OE04, OE10 e OE14 \\
\hline
\end{tabular}

Fonte: Plano de Diretor de Tecnologia da Informação do MPS (2014-2015) e análise do autor. 


\section{Ministérios que possuem somente o PDTI Ministério das Comunicações}

O Ministério das Comunicações (MC) descreve sua missão da seguinte forma: " desenvolver, de forma transparente e participativa, políticas públicas que promovam o acesso aos serviços de comunicações, contribuindo para o crescimento econômico, a inovação tecnológica e a inclusão social no Brasil".

Como o MC não possui o instrumento PE, a análise foi baseada no PPA 2012-2015, que descreve os objetivos estratégicos a serem perseguidos pelo MC. O Quadro 8 apresenta esses objetivos estratégicos.

Quadro 8 - Objetivos Estratégicos do MC/PPA
\begin{tabular}{|c|l|}
\hline Código & Descrição dos Objetivos \\
\hline OE01 & $\begin{array}{l}\text { Expandir a infraestrutura e os serviços de comunicação social eletrônica, } \\
\text { telecomunicaçôes e serviços postais, promovendo o acesso pela população e } \\
\text { buscando as melhores condições de preço, cobertura e qualidade. }\end{array}$ \\
\hline OE02 & $\begin{array}{l}\text { Promover o uso de bens e serviços de comunicações, com ênfase nas } \\
\text { aplicaçōes, serviços e conteúdos digitais criativos para potencializar o } \\
\text { desenvolvimento econômico e social do País. }\end{array}$ \\
\hline OE03 & $\begin{array}{l}\text { Estimular a diversidade, a pluralidade e a competição entre meios e agentes } \\
\text { da área das comunicaçôes por meio da revisão do arcabouço regulatório } \\
\text { e de ações que busquem oferecer o maior número possível de fontes de } \\
\text { informação aos brasileiros. }\end{array}$ \\
\hline
\end{tabular}

Fonte: PPA (2012-2015).

Após análise dos objetivos estratégicos definidos pelo MC, compreende-se que estes estão alinhados com a missão apresentada pelo órgão. Não obstante, estes não expressam a visão estratégica do Ministério em sua totalidade, pois não há objetivos que: a) abordam ações para a capacitação dos servidores do órgão; b) que visam ao aperfeiçoamento na aplicação dos recursos financeiros; c) que visem à segurança das informações dos serviços de comunicação social eletrônica, telecomunicações e serviços postais; e, d) fiscalizem tais serviços.

O Quadro 9 apresenta os objetivos estratégicos de TI que o MC planejou desenvolver nos anos de 2013 a 2015 em seu PDTI.

Quadro 9 - Objetivos Estratégicos da TI do MC

\begin{tabular}{|c|l|}
\hline Código & Descrição do objetivo \\
\hline OETI01 & Promover a governança de TI no MC. \\
\hline OETI02 & $\begin{array}{l}\text { Evoluir no atendimento das áreas finalísticas do MC, balanceando o } \\
\text { portfólio de projetos e serviços a partir das diretrizes do planejamento } \\
\text { estratégico do ministério. }\end{array}$ \\
\hline OETI03 & Aprimorar a gestão de TI no MC. \\
\hline
\end{tabular}

\begin{tabular}{|c|l|}
\hline Código & Descrição do objetivo \\
\hline OETI04 & $\begin{array}{l}\text { Redefinir a estrutura organizacional e a composição das equipes envolvi- } \\
\text { das nas atividades de TI do MC. }\end{array}$ \\
\hline 0 ETI05 & Melhorar continuamente os serviços de TI no MC. \\
\hline OET106 & $\begin{array}{l}\text { Estabelecer e aprimorar a(s) arquitetura(s) de referência para a TI do MC, } \\
\text { de forma alinhada com as diretrizes do governo federal. }\end{array}$ \\
\hline OET107 & $\begin{array}{l}\text { Prover soluçães confiáveis e disponíveis que ofereçam recursos de: } \\
\text { mobilidade, colaboração, desmaterialização de processos e transparência } \\
\text { para com a sociedade. }\end{array}$ \\
\hline OETI08 & Prover a segurança da informação e comunicação no MC. \\
\hline Fonte: PETI - PDTI do MC (2013 a 2015).
\end{tabular}

Após essa análise, observa-se que os objetivos estratégicos de TI se encontram parcialmente alinhados com os objetivos estratégicos institucionais. Não foi encontrado um dos oito objetivos propostos pela TI nos objetivos estratégicos institucionais. O Quadro 10 apresenta o alinhamento que se evidencia entre os objetivos estratégicos institucionais e os objetivos estratégicos de TI.

Quadro 10 - Alinhamento entre os Objetivos Estratégicos e Objetivos Estratégicos da TI do MC

\begin{tabular}{|c|c|}
\hline Código - Objetivo Estratégico TI & Código - Objetivo Estratégico Institucional \\
\hline OET101 & OE01, 0E02 \\
\hline OETI02 & OE01, 0E02 \\
\hline OET103 & OE01, 0E02 \\
\hline OET104 & Não possui \\
\hline OET105 & OE01 \\
\hline OET106 & OE01, 0E02 \\
\hline OET107 & OE02 \\
\hline OETI08 & OE01, 0E02 \\
\hline
\end{tabular}

Fonte: Análise do autor.

\section{Ministério do Desenvolvimento Social e Com- bate à Fome}

O Ministério de Desenvolvimento Social e Combate à Fome (MDS) descreve sua missão da seguinte forma "promover a inclusão social, a segurança alimentar, a assistência integral e uma renda mínima de cidadania às famílias que vivem em situação de pobreza".

Como o MDS também não possui o instrumento PE, a análise foi baseada no PPA 2012-2015 que descreve os objetivos estratégicos a serem perseguidos pelo MDS. O Quadro 11 apresenta esses objetivos estratégicos. 
Quadro 11 - Objetivos Estratégicos do MDS/PPA

\begin{tabular}{|c|c|}
\hline Código & Descrição dos Objetivos \\
\hline OE01 & $\begin{array}{l}\text { Melhorar as condições socioeconômicas das famílias pobres e, sobretudo, } \\
\text { extremamente pobres, por meio de transferência direta de renda e da arti- } \\
\text { culação com outras políticas promotoras de emancipação. }\end{array}$ \\
\hline OEO2 & $\begin{array}{l}\text { Localizar e caracterizar as famílias consideradas como público-alvo dos } \\
\text { programas de transferência de renda e dos programas sociais do Governo } \\
\text { Federal voltados à população de baixa renda, e realizar a gestão e manuten- } \\
\text { ção de suas informações socioeconômicas, por meio do desenvolvimento e } \\
\text { aperfeiçoamento de metodologias, instrumentos e sistemas de informaçõ̃es, } \\
\text { com objetivo de subsidiar o planejamento e a implementação de políticas de } \\
\text { combate à pobreza e à desigualdade social. }\end{array}$ \\
\hline OE03 & $\begin{array}{l}\text { Ampliar } 0 \text { acesso das famílias em situação de vulnerabilidade social ao } \\
\text { acompanhamento familiar e ao atendimento pela proteção básica e especial; } \\
\text { qualificar os serviços e promover sua articulação com os benefícios e transfe- } \\
\text { rência de renda; assegurar o funcionamento da rede de proteção social básica } \\
\text { e expandi-la nos territórios intramunicipais e de extrema pobreza; e induzir } \\
\text { a estruturação de unidades públicas de prestação de serviços socioassisten- } \\
\text { ciais, de acordo com padrões estabelecidos nacionalmente. }\end{array}$ \\
\hline OE04 & $\begin{array}{l}\text { Ampliar } 0 \text { acesso das famílias e indivíduos em situação de riscos sociais e } \\
\text { violação de direitos aos serviços de acompanhamento e atendimento espe- } \\
\text { cializados; assegurar o funcionamento e expandir a rede de proteção social } \\
\text { especial; qualificar os serviços ofertados e induzir a estruturação da rede de } \\
\text { unidades de prestação de serviços de média e alta complexidade, de acordo } \\
\text { com padrões estabelecidos nacionalmente. }\end{array}$ \\
\hline OE05 & $\begin{array}{l}\text { Conceder benefícios assistenciais a indivíduos que atendam aos critérios } \\
\text { estabelecidos na legislação, contribuir para a integração entre os benefícios } \\
\text { assistenciais e os serviços da rede socioassistencial e das demais políticas se- } \\
\text { toriais e qualificar a regulamentação do Benefício de Prestação Continuada } \\
\text { da Assistência Social (BPC) e dos benefícios eventuais. }\end{array}$ \\
\hline 0E06 & $\begin{array}{l}\text { Coordenar a gestão do Sistema Único de Assistência Social (SUAS), apoiando } \\
\text { e acompanhando sua implementação nas demais esferas de governo, assim } \\
\text { como organizar e coordenar a Vigilância Social, para o monitoramento das } \\
\text { vulnerabilidades, riscos sociais e violações de direitos, dos padrões dos bene- } \\
\text { fícios e ações ofertadas pela política de assistência social. }\end{array}$ \\
\hline OE07 & $\begin{array}{l}\text { Consolidar a organização de circuitos locais de produção, abastecimento e } \\
\text { consumo, por meio da expansão e estruturação da rede de equipamentos, } \\
\text { ações e serviços públicos de comercialização, alimentação e nutrição sob a } \\
\text { ótica do Direito Humano à Alimentação Adequada. }\end{array}$ \\
\hline OE08 & $\begin{array}{l}\text { Promover } 0 \text { acesso à alimentação adequada e fomentar a inclusão socioe- } \\
\text { conômica de agricultores familiares, mulheres rurais, povos e comunidades } \\
\text { tradicionais e povos indígenas, por intermédio da ampliação da sua parti- } \\
\text { cipação, prioritariamente dos mais pobres, no abastecimento dos mercados } \\
\text { institucionais, da rede socioassistencial e dos equipamentos públicos de } \\
\text { alimentação e nutrição. }\end{array}$ \\
\hline 0E09 & $\begin{array}{l}\text { Fomentar e estruturar a produção familiar e a inclusão produtiva, especial- } \\
\text { mente dos agricultores familiares, povos indígenas e povos de comunidades } \\
\text { tradicionais em situação de insegurança alimentar e nutricional, de forma a } \\
\text { gerar alimentos, excedentes de produção e renda. }\end{array}$ \\
\hline
\end{tabular}

Fonte: PPA (2012-2015).

Após análise dos objetivos estratégicos definidos pelo MDS, compreende-se que estes estão alinhados com a missão apresentada pelo órgão. No entanto, não demonstram uma visão estratégica para o órgão. Observa-se que o foco dos esforços está, somente, em desenvolver soluções que visam à melhoria e ampliação de ações e programas sociais perante o seu público alvo na sociedade brasileira, e não há objetivos que promovam o aperfeiçoamento na aplicação dos recursos financeiros, objetivos que visem à segurança das informações dos programas sociais e demais informações do órgão. Por fim, objetivos que abordam ações para a capacitação dos servidores do órgão.

O Quadro 12 apresenta os objetivos estratégicos de TI que o MDS planejou desenvolver nos anos de 2014 e 2015 em seu PDTI.

Quadro 12 - Objetivos Estratégicos da TI do MDS

\begin{tabular}{|c|l|}
\hline Código & Descrição do Objetivo \\
\hline OETI01 & Aprimorar os processos de gestão e governança de TI. \\
\hline OETI02 & Melhorar os controles da gestão de contratos e serviços de TI. \\
\hline OETI03 & Garantir a integridade dos dados e informações. \\
\hline OETI04 & Prover soluções de segurança da informação e infraestrutura tecnológica. \\
\hline OETI05 & Desenvolver e manter os sistemas de informações. \\
\hline OETI06 & Desenvolver competências gerenciais e técnicas dos servidores. \\
\hline OETI07 & Gerir os recursos orçamentários de TI. \\
\hline
\end{tabular}

Fonte: Plano de Diretor de Tecnologia da Informação do MDS (2014-2015).

Após essa análise, observa-se que os objetivos estratégicos de TI estão parcialmente alinhados com os objetivos estratégicos institucionais. Não foram encontrados três dos sete objetivos propostos pela TI nos objetivos estratégicos institucionais como mostra o Quadro13.

Quadro 13 - Alinhamento entre os Objetivos Estratégicos e Objetivos Estratégicos da TI do MDS

\begin{tabular}{|c|c|}
\hline $\begin{array}{c}\text { Código - Objetivo } \\
\text { Estratégico TI }\end{array}$ & Código - Objetivo Estratégico Institucional \\
\hline OETI01 & OE06 e 0E02 \\
\hline OETI02 & Não possui \\
\hline OET103 & OE02 e 0E05 \\
\hline OETI04 & OE05 \\
\hline OETI05 & OE02 \\
\hline OET106 & Não possui \\
\hline OETI07 & Não possui \\
\hline
\end{tabular}

Fonte: Análise do autor.

\section{Conclusão}

Por meio das definições apresentadas no início do trabalho, entende-se que os objetivos estratégicos institucionais devem direcionar quais as ações que o órgão deve perseguir para cumprir sua missão perante a sociedade. Partindo dessa premissa e com base nos dados levantados, conclui-se que os Ministérios da Saúde e da Previdência Social estão com seus instrumentos PE e PDTI alinhados 
e que os objetivos estratégicos definidos por ambos. Já o mesmo não acontece para os Ministérios da Comunicação e Desenvolvimento Social e Combate à Fome.

Quando esse alinhamento não existe, evidencia-se a iniciativa da área de TI em executar ações que não são demandadas pela estratégia da organização. Esse descolamento entre Planejamento Estratégico e as ações de TI podem significar que o primeiro foi feito parcialmente, não tratando de diretrizes importantes, ou que a TI decidiu por executar ações não necessárias para a organização. Considerando que não existem recursos financeiros ilimitados, essas ações não estratégicas vão disputar recursos financeiros necessários para as outras ações estratégicas.

Em suma, reafirma-se que a área de TI expressa um papel estratégico nas organizações e que, atualmente, sua importância vai além de desenvolver softwares e realizar a manutenção de hardwares. Quando a TI assume o protagonismo de realizar ações que atendam as diretrizes estratégicas, ela se torna mais importante para a organização e mais competitiva na disputa dos recursos financeiros necessários. No caso de órgãos públicos, alcança-se, como resultado, uma melhor prestação de serviço aos seus cidadãos.

\section{Referências}

AUDY, Jorge Luiz Nicolas; BRODBECK, Ângela Freita. Sistemas de informação: planejamento e alinhamento estratégico nas organizações. Disponível em: <http://books. google.com.br/books?id=tmZ21u81 reAC\&printsec=frontcover\&hl=ptPT\&source=gbs_ge_summary_r\&ca$\mathrm{d}=0 \# \mathrm{v}=$ onepage \&q\&f=false $>$. Acesso em: 12 jul. 2014.

BARROS, Fábio Gomes. Elaboração de PDTI. Rio de Janeiro: RNP/ESR, 2014. Disponível em: <https:/pt.scribd. com/doc/220992268/Elaboracao-de-PDTI >. Acesso em: 12 fev. 2015.

BRASIL. Decreto Lei $n^{\circ}$ 200, de 25 de fevereiro de 1967. Dispõe sobre a organização da Administração Federal, estabelece diretrizes para a Reforma Administrativa e dá outras providências. Brasília, 25 fev. 1967. Disponível em: <http://www.planalto.gov.br>. Acesso em: 12 jul. 2014.

CHIAVENATO, I.; SAPIRO, A. Planejamento estratégico: fundamentos e aplicações. Rio de Janeiro: Elsevier, 2003.

CHIAVENATO, Idalberto. Introdução à Teoria Geral da Administração: uma visão abrangente da moderna admi- nistração das organizações. 7. ed. Rio de Janeiro: Elsevier, 2003.

DAYCHOUM, Merhi. 40 ferramentas e técnicas de gerenciamento. Rio de janeiro: Brasport, 2007. Disponível em: <http://books.google.com.br/books?id=jQ_JOBtvgBAC\&printsec $=$ frontcover $\&$ hl $=$ pt $-B R \&$ source $=g b s \_g e$ summary_r\&cad $=0 \# \mathrm{v}=$ onepage $\& \mathrm{q} \& \mathrm{f}=$ false $>$. Acesso em: 20 nov. 2014.

FOINA, Paulo Rogério. Tecnologia de informação: planejamento e gestão. 3. ed. São Paulo: Atlas, 2013.

LAURINDO, F. J. B. et al. O Papel da Tecnologia da Informação (TI) na Estratégia das Organizações. Gestão \& Produção, São Paulo, v. 8, n. 2, p. 160-179, 2001. Disponível em: <http://www.scielo.br/pdf/gp/v8n2/v8n2a04. pdf>. Acesso em: 29 set. 2014.

MINTZBERG, Henri et al. O processo da estratégia: conceito, contexto e casos selecionados. Porto Alegre: Artmed, 2007. Disponível em: <http://books. google.com.br/books?id=6mPVdRmBYdIC\&printse$\mathrm{c}=$ frontcover \&dq=\%20inauthor:\%22Henry+Mintzber$\mathrm{g} \% 22 \& \mathrm{hl}=\mathrm{pt}-\mathrm{R} \& \mathrm{sa}=\mathrm{X} \& \mathrm{ei}=\mathrm{gfxcVNe} 1 \mathrm{KoymgwS7ro} \% 20$ G4Cw\&ved=0CDEQ\%206AEwAw\#v=onepage\&q\&f=false >. Acesso em: 14 nov. 2014.

MINTZBERG, Henri. Ascensão e queda do planejamento estratégico. Porto Alegre: Bookman, 2004.

PORTER, Michael E. Competição: estratégias competitivas essenciais. 1999. Disponível em: <https://books. google.com.br/books?id=SMfDDZCuClEC\&print$\mathrm{sec}=$ frontcover $\& \mathrm{dq}=$ inauthor: $\% 22 \mathrm{Michael}+\mathrm{E} .+$ Porter\%22\&hl=pt-BR\&sa=X\&ved=0CB0Q6AEwAGoVChMI15XpsOrRxwIVgxuQCh2J9gEd\#v=onepage\&q\&f=false>. Acesso em: 29 set. 2014.

RASMUSSEN, U. W. Manual da metodologia do planejamento estratégico: uma ferramenta científica da transição empresarial do presente para o futuro adotada para o âmbito operacional brasileiro. São Paulo: Aduaneiras, 1990.

REZENDE, Denis A. Alinhamento estratégico da tecnologia da informação ao planejamento estratégico: proposta de um modelo de estágios para governança em serviços públicos. RAP. Revista Brasileira de Administração Públi- 
ca, Brasília, v. 38, n. 4, p. 519-542, 2004. Disponível em: <http://bibliotecadigital.fgv.br/ojs/index.php/rap/article/ view/6759/5341>. Acesso em: 20 set. 2014.

RIBEIRO, Hélio Alessandro; ANDRADE, Macson Alysson Vieira. A importância do planejamento estratégico nas organizações atuais. Disponível em: <http://www.periodicos.cesg.edu.br/index.php/gestaoeengenharia/article/ view/63pdf>. Acesso em: 20 nov. 2014.

SISP. Guia de Elaboração de PDTI do SISP. Disponível em: <http://www.sisp.gov.br/guiapdti/wiki/Documento>. Acesso em: 09 fev. 2015.
SISP. Instrução Normativa No 4, de 19 de maio de 2008. Dispõe sobre o processo de contratação de serviços de Tecnologia da Informação pela Administração Pública Federal direta, autárquica e fundacional. Brasília, 29 maio. 2008. Disponível em: <http://www.governoeletronico.gov.br/>. Acesso em: 12 jul. 2014.

WEBSTER, I. L.; CASTRO, A. C. M. Planejamento $e$ gestão estratégica de TI. Rio de Janeiro: Escola Superior de Rede, 2012. Disponível em: <http://pt.scribd.com/ doc/85806152/Planejamento-e-Gestao-Estrategica-de-TI\#scribd>. Acesso em: 15 fev. 2015.

WRIGHT, Peter; KROLL, J. Mark; PARNELL, John. Administração estratégica. São Paulo: Atlas, 2000. 